\title{
"At This Level, Students Should Not Be "Taught": Connected and Facilitative Teaching Approaches Preferred by Women Graduate Students
}

Sonya Corbin Dwyer, (E-mail: Sonya.Dwyer@uregina.ca), University of Regina, Canada Jody Burnett, University of Regina, Canada

\begin{abstract}
Almost $72 \%$ of 326 women respondents considered the teaching approaches in their graduate programs effective. One meta-theme and 4 themes are described and discussed.
\end{abstract}

\section{Graduate Women: The Canadian Context}

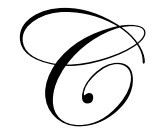

anadian women's university participation rate doubled from $10 \%$ to $20 \%$ between 1975 and 1992 (although it has remained relatively stable since then) (Mandel \& Berkowitz, 1999).

Women currently make up the majority of full-time students in Canadian universities. Statistics from 1996 indicate women made up 50\% of those with a Bachelor's or first professional degree compared with only $23 \%$ of those with a doctorate (Statistics Canada, 2000). In 1997, while almost $60 \%$ of bachelor's degrees and $51 \%$ of master's degrees were earned by women, women only earned $36 \%$ of doctoral degrees (Mandel and Berkowitz, 1999). Why do many women with master's degrees not continue in academia? The literature offers some explanations for this drop-off and for why the educational experiences of women in graduate school differ from men (Nerad \& Cerny, 1999). As a result, educators and researchers have come to understand more about the importance of the learning environment for the success of graduate students, particularly women (Nerad \& Cerny). This paper highlights one aspect of the university learning environment, teaching approaches, by describing the ones women graduate students consider to be effective.

\section{Research Approach}

A questionnaire (adapted from Lussier, 1995) was mailed to all women who had been registered as master's students in two cohorts, five years apart, at one Canadian university. These cohorts were chosen because students would either be finished or at the end of the programs, or have withdrawn. This time lapse would provide students with the opportunity to reflect on their experiences in their program of studies.

The 345 respondents represented a wide range of graduate students from a variety of disciplines, including Arts and Humanities, Business Administration, Education, Engineering, Fine Arts, Physical Education and Recreation Sciences, and Social Work. 
Nearly $17 \%$ of the women were 25 years of age or younger when they entered their master's programs. Almost $39 \%$ of the women were between ages of 35 and 45 upon admission while slightly more than $14 \%$ of the women were 46 years of age or older. Prior to starting their graduate degrees, $67 \%$ were employed full-time, 13\% were employed part-time, and $16 \%$ were students and not in the labour force. Approximately $30 \%$ of the women started their master's programs one year or less after completing their bachelor's degrees; $16 \%$ began their graduate degrees ten or more years after completing their undergraduate studies. Nearly $15 \%$ of respondents started their master's degrees prior to 1990 . About $23 \%$ of the students completed their programs on a full-time basis while $48 \%$ were part-time students. The rest went both full-time and part-time at some point during their programs. Almost $45 \%$ of the women completed their graduate degrees in three years or less while $22 \%$ took 6 years or more.

The questionnaire contained the open-ended question "Were the teaching approaches used in your program effective for you? $\square$ Yes $\square$ No Please explain." Of the $94 \%$ of respondents who answered this question, 72.1\% answered 'yes;' $11.3 \%$ replied 'no' and 16.6\% checked 'yes' and 'no.' Thematic analysis was conducted on the women's written responses.

\section{Students Should Not Be Taught}

"Learning [was] facilitated [emphasis added] by constructive advice and criticism. At this level, students should not be "taught." (woman graduate student)

The meta-theme of effective graduate teaching was that Students should not be taught, that is, student learning should be facilitated. Depending on one's teaching philosophy, 'facilitation' and 'teaching' may be viewed as one-and-the-same or as completely different. Nevertheless, the results of the study demonstrate the need for teaching strategies used in graduate education to reflect facilitation. Facilitation, as defined by Webster's On-line dictionary, is "The act of assisting or making easier the progress or improvement of something." In teaching, it is a process of enabling groups of people to work together to achieve individually devised goals and objectives. The role of the facilitator, or teacher, is to guide and assist the learning process, not control it. Facilitation is a "form of instruction," and is intended to provide an inviting learning climate for students (Grudens-Schuck, 2003, p.10).

It is interesting to note that some women recognized the effective teaching approaches as being grounded in adult learning theory: "Included a wide range of adult learning centered techniques;" "I appreciated that many professors knew about adult learning theory and treated us as such;" "Teacher adopted an adult education model." Likewise, when ineffective teaching was demonstrated, some of the students felt that "university professors should take some courses in teaching. Many of these individuals lack good communication skills and don't understand the learning process (how to best help others learn)."

Not surprisingly, learning preferences often dictated what teaching approaches were deemed effective: "I like hands-on experience. Very visual. Lab courses offered this." Some students were "looking forward to the practical training-I had had enough of theory. Also, practical learning is a strength of mine."

Each of the themes described in this section, Self-directed learning and independent study, Small class sizes, allowing for group work and discussion, Students teaching students, and Variety is key, illustrates teaching approaches deemed 'effective' by these women graduate students which do not always have the professor 'teaching.' Rather, these approaches demonstrate facilitation. 


\section{Self-Directed Learning and Independent Study}

Many women commented on the amount of self-directed learning at the graduate level: "Most of the courses were very self-directed. I was allowed to choose work relevant to me..." This aspect was seen as a component of graduate studies: "I am self-motivated and you have to be to be successful in the program." Perhaps this is a feature of graduate studies which attracts students, or is a learning preference of students attracted to graduate studies: "The classes were very self-directed (i.e., student) which appeals to me;" "Program was geared toward independent work and research which was a good fit for me."

This characteristic of graduate studies was generally well-liked and appreciated: "Self-directed courses suit my learning style best;" "There was a real sense of independence. I knew what the job was. My advisors kept opening doors and I walked through with confidence." Autonomous, or self-directed, learning is particularly common amongst adult learners. Most individuals have developed a level of independence in adulthood that provides them with the capability and willingness to be independent in their learning as well (Moore, 1986). Learning environments can be designed to incorporate an adult student's experiences, interests and self-motivations to learn. These women reported that effective professors used approaches that were inclusive of student interaction and participation, and that these strategies represented a large component of the teaching, and therefore learning, processes. The benefits of self-directed learning extend beyond student satisfaction. Literature contends that self-directed learning influences students to become more responsible, more creative, more disciplined and more goaloriented in their educational endeavours (Abdullah, 2001).

\section{Small Class Sizes, Allowing For Group Work and Discussion}

Another feature of effective graduate teaching and learning that was cited frequently was "small classes utilizing group work and discussion." This aspect was seen as promoting "learn[ing] as an academic community." "The classroom participation" was viewed as "allow[ing] for individual differences in learning styles" in the ways in which students chose to contribute. It was deemed an effective teaching strategy as "the small and open class settings allowed student to discuss, explore and share ideas." "The variety of points of view and relevant experiences of the group added more diversity and perspective to the subject at hand." Small class sizes allow for personalization of instruction: "The class size was small. There was more interaction and feedback." Of course, this approach can be used within other teaching methods: "I like interactive discussions with the class rather than straight lectures." It appears professors facilitated the learning process through the use of group work, which, as the literature points out, enhances responsibility and creativity amongst students (Leith, 2002).

A little over $40 \%$ of the women indicated that a "lack of a support network of other graduate students" affected their progress in their master's program and $49 \%$ of them said it had a 'moderate' or 'major' effect. The development of cohorts and support networks appears to be important for direction and motivation, because as one woman wrote, "sometimes you get lost." The value of peer support for graduate women may be one of the main reasons they consider small classes and group work so effective.

In general, small class size is believed to have an overall positive affect on student learning. Research asserts that small classes are academically advantageous and promote classroom behavior that improves learning. It is believed that this can be attributed to the increased student interaction and active engagement with peers facilitated within a smaller classroom setting (Finn, 1997).

Again, like all teaching approaches, one method does not work for everyone: "I would have enjoyed hearing more from the profs themselves instead of having 'activities'...centered around the grad students." This desire to 'hear more' from professors is discussed further in the next section. 


\section{Students Teaching Students}

Overall, the women recognized that at the graduate level they each had valuable knowledge and experience to share with one another: "Unlike my undergraduate program, which emphasized teacher teaching students, my graduate program, for the most part, encouraged a sharing of professional experience/expertise among students." They saw that many of the teaching approaches they considered to be effective allowed for "connecting with other students from other work backgrounds gave me opportunity to consider different perspectives." Another commented that this approach to learning was unique to graduate studies: "We (students) were treated as adults with an ability to think instead of just parroting what we were taught (as in high school and undergraduate studies)."

While most agreed that "Some of the classes were good because they encouraged a lot of input from my classmates (professionals) who had a lot to offer," they way in which this 'sharing' was accomplished or the amount of sharing that occurred in graduate courses was more controversial. Many students agreed "Teaching material you have to learn is the most effective method of recalling/retaining information over time;" "Presentations-learned from each other...Challenged me to provide useful, practical info for others." It seems to be the degree to which professors relied on this teaching approach that changed it from effective to ineffective: "the teaching approach used by the professors was to have students present on topics. That seemed to be the only strategy. I think I could have learned more from the professors if they had shared their experiences, and talked about what was reality and practical." Professor input was still seen as a necessary component of the learning process: "The teaching process in most classes was predictable with $50-75 \%$ of class time spent on student presentations. While I value the diverse perspectives this activity offers, I would have benefited more if professors 'debriefed' such presentations by reflecting on key terms, concepts, and theories. The norm was that simple applause ended the lesson." Others saw this strategy as a cop-out for professors: "Students have to rely on teaching each other in class. Some of this is positive, but not when the professors do not take any responsibility for teaching." More professor involvement and explaining the theory behind the teaching approach may help clarify this method, and make it more meaningful to students.

\section{Variety is Key}

While variety is the spice of life, it appears to also be the spice of teaching approaches. Many women did not name one teaching method which appealed to them but named several "A variety of teaching strategies: group work, discussions, reflections, readings, writing, independent research projects..." Were the many teaching strategies effective because they were varied or varied which made them effective? "Many approaches were often used. The professors did a good job of teaching to different learning styles;" "We also had a variety of experiences/assignments that allowed me to utilize my areas of strength."

Certainly no one teaching approach was consistently named as effective by all of the respondents. And each approach was also described as 'ineffective' by at least one graduate student. So what can be learned from this? One woman summarized it this way: "Some professors were excellent at incorporating a multi-faceted learning style and came to class prepared and ready to share knowledge. Professors most successful at getting knowledge across used a variety of strategies from lecture, small group work, individual presentations, group presentations, reading analysis and just instilling in students their enthusiasm and knowledge about the course they were teaching." 


\section{Discussion}

As noted earlier, each of the four themes illustrates teaching approaches that are facilitative in nature. Kunkel (1994) emphasized "Women need community... Women need to work in partnership with individuals and with the university" (p. 19). Facilitative approaches to teaching typically builds community by combating alienation and ostracism because as Kunkel pointed out, "community means a safe, aware, supportive, and equitable atmosphere for women" (p. 19).

The findings of the effective teaching approaches Small class sizes, allowing for group work and discussion and Students teaching students reported by women in this study appear to be consistent with much of the research on women's learning. In their review of the literature, one of the key themes found by Hayes and Flannery's (1995) was 'women as connected learners.' They stated that women prefer to learn in ways that allow them to connect new concepts to personal experience and to engage in communal as opposed to solitary knowledge-building.

Wiest (1999) found that women tend to construct knowledge and express ideas in a "more relational than a discrete or objectified manner" (p. 31). She recommends using instructional methods that match women's working and learning styles, such as collaborative endeavors like group work for discussions, presentations, and papers. Wiest does caution that mixed-gender groups can oppress women and advises monitoring and structuring these groups carefully.

Wiest (1999) highlighted that graduate women are especially prone to isolation because, at advanced levels of study, they are often a numerical minority. As noted earlier, responses to another question on our survey indicated the importance of peer support during the graduate program. Perceived isolation may also speak to why women reported Small class sizes, allowing for group work and discussion as an effective teaching method.

"Adult education theory places a high value on the impact of prior experience on current learning encounters" (Saul, 1992, p. 47). The women in this study spoke of the value of students sharing their perspectives with one another. However, many said this should be moderated with professors sharing their experiences as well. Therefore, the results of this study should encourage faculty and students to both share their knowledge so that effective learning can take place.

Some of the women in this study commented that effective teaching included "being able to share opinions that differed from the professors." This aspect of teaching is similar to what Belenky, Clinchy, Goldberger, and Tarule (1986) refer to as 'connected teaching:' "Connected teachers welcome diversity of opinion in class discussion. Many of the women...spoke with appreciation of teachers who refrained from 'inflicting' (a common term) their own opinions on the students" (p. 223). It appears this idea of connected teaching is necessary in helping to create effective learning environments for graduate women.

'Women as connected learners' appears contradictory to Self-directed learning and independent study. However, upon closer examination, the self-directed aspect seems to do more with freedom to choose what topic(s) to study rather than with studying on one's own. Therefore, this theme fits with a theme found in the work of Saul (1992): "Professors" attitudes and actions set a climate for learning" (p. 46). Independence to choose what subject to study may give the message that the professor values the student's experience and knowledge, and indirectly sets up a cooperative spirit.

It is important to note that there is not a single 'women's way of knowing.' Learning may depend on context and past experiences (Hayes \& Flannery, 1997). Accordingly, the theme Variety is key acknowledges the value of using more than one method of teaching. Both students and faculty might 
benefit from class discussions about different teaching approaches. These discussions may help women graduate students appreciate their strengths as learners and enable educators to build upon these strengths in formal learning situations (Hayes \& Flannery).

\section{Conclusion}

Listening to the voices of graduate women is a critical component in examining how our educational system influences their academic decisions (Corbin Dwyer, Sabatini, \& Mohr, 1997). Haynes and Flannery (1997) found that "studies which investigated women's own perspectives on their learning experiences were almost nonexistent" (p. 61). They advocated for women's subjective experiences as a "source of information in the study of something as complex and personal as learning" (p. 62). While this study contributes to this body of literature, there is a clear need for more research. In particular, what teaching methods are considered effective by women of color, by women with physical impairments, and by women in other unrepresented groups?

"It is not enough for higher-education institutions to recruit and admit female students. Universities also must examine issues of retention, investigating influential factors that help or hinder female graduate students in their pursuit of advanced degrees" (Wiest, 1999, p. 33). Teaching methods should be at the top of this list of influential factors. 


\section{References}

- Abdullah, M. (2001, December ). Self-directed learning. ERIC Digest. (Eric Doc: D169).

- Belenky, M., Clinchy, B., Goldberger, N., and Tarule, J. (1986). Women's ways of knowing: The development of self, voice, and mind. New York: Basic Books.

- Corbin Dwyer, S., Sabatini, L., \& Mohr, A. (1997). Who's that girl?: Exploring a profile of women graduate students. Paper presented at the annual meeting of the Canadian Society for the Study of Education, St. John's, Newfoundland.

- Finn, J. (1997). Class size: What does research tell us? A Digest of Research from the Laboratory of Student Success. No. 207. Philadelphia, PA: Temple University Center for Research in Human Development and Education.

- Grudens-Schuck, N. (2003). Facilitation as the main form of instruction: The case of the odd duck. The Agricultural Education Magazine, 76 (2), 10.

- Hayes, E., \& Flannery, D. (1995). Adult women's learning in higher education: A critical review of scholarship. Initiatives, 57 (1), 29-37.

- Hayes, E., \& Flannery, D. (1997). Narratives of adult women's learning in higher education: Insights from graduate research. Initiatives, 58 (2), 61-80.

- Kunkel, C. (1994). Women's needs on campus: How universities meet them. Initiatives, 56 (2), $15-28$.

- Leith, K. (2002). Adult learning styles and the college classroom. Paper presented at the Annual Meeting of the American Psychological Association. Chicago, IL., August 22-25.

- Lussier, T. C. (1995). Doctoral students at the University of Manitoba: Factors affecting completion rates and time to degree by gender and field of study. Unpublished Master's thesis, Division of Post-secondary Studies, University of Manitoba, Winnipeg, MB.

- Mandel, C., \& Berkowitz, P. (1999, August/September). Gender gap. University Affairs,17-21.

- Moore, M. (1986). Self-directed learning and distance education. Journal of Distance Education ,1 (1).Retrieved August 1, 2004 from http://cade.athabascau.ca/voll.1/moore.html

- Nerad, M., \& Cerny, J. (1999). Widening the circle: Another look at women graduate students. Communicator, 32 (6), 1-7.

- Statistics Canada. (2000). Women in Canada: A gender-based statistical report. Ottawa: Author.

- Webster's On-Line Dictionary. Retrieved July 31, 2004 from http://www.websters-onlinedictionary.org

- Wiest, L. (1999). Addressing the needs of graduate women. Contemporary Education, 70 (2), 3033.

\section{Authors’ Note}

We gratefully acknowledge the funding provided for this research by the Social Sciences and Humanities Research Council (SSHRC) of Canada, and additional support provided by the Humanities Research Institute, University of Regina. 


\section{$\underline{\text { Notes }}$}

